\section{Methylation analysis of fragile $X$-related epigenetic elements may provide a suitable newborn screening test for fragile $X$ syndrome}

\section{To the Editor:}

In a recent issue of this Journal, Coffee et al. ${ }^{1}$ provides an overview of tests currently available for detection of the fragile $\mathrm{X}$ mutation and their uses. The article emphasizes that CGG-based tests are inappropriate for population-based fragile $\mathrm{X}$ newborn screening, because of the counseling and ethical challenges created by the detection of premutation carriers and the detection of females with full mutations who may never develop symptoms. Coffee et al. suggests that testing for aberrant methylation is a preferable option for newborn screening because it avoids the detection of small allele carriers, a significant fraction of whom will be destined to develop late onset conditions, but that quantification of the FMR1 protein might provide the only solution.

We have recently developed a novel PCR-based test that examines methylation patterns of fragile X-related epigenetic elements (FREE) using assisted laser desorption/ionizationtime of flight mass spectrometry. The FREE methylation test has been closely related to FMR1 protein expression and identified fragile $\mathrm{X}$ syndrome (FXS)-affected males and females with $100 \%$ specificity in our small study ( 75 male and 50 female subjects) consisting of samples from all categories of expanded alleles. ${ }^{2}$ Importantly, the assisted laser desorption/ionizationtime of flight-based test has been shown to exclude from detection the subset full mutation females who are clinically unaffected, high functioning males with unmethylated full mutations, and all individuals with gray zone and/or premutation alleles.

Given that there is increasing evidence for the benefits of early diagnosis and treatment for FXS, ${ }^{3}$ the FREE methylation test may offer an attractive solution to the technical and ethical problems that have prevented the introduction of FXS newborn screening.

\section{ACKNOWLEDGMENTS}

This study was supported by the National Institutes of Child Health and Human Development Grant HD 36071 and Australian National Health and Medical Research Council (NHMRC) project Grant 330400 (to D.Z.L.).

David E. Godler, PhD

The Chromosome and Chromatin Research Laboratory Murdoch Childrens Research Institute Royal Children's Hospital

Howard R. Slater, PhD

VCGS Cytogenetics Laboratory Murdoch Childrens Research Institute

Royal Children's Hospital

Department of Paediatrics

University of Melbourne/Parkville

David Amor, MD, PhD

Department of Paediatrics

University of Melbourne/Parkville

Victoria, Australia

Genetic Health Services Victoria

Murdoch Childrens Research Institute

Danuta Z. Loesch, MD, PhD

The Chromosome and Chromatin Research Laboratory

Murdoch Childrens Research Institute

Royal Children's Hospital

Melbourne/Parkville, Victoria, Australia

School of Psychological Science

La Trobe University

Melbourne, Victoria, Australia

Disclosure: The author declares no conflict of interest.

\section{REFERENCES}

1. Coffee B. Commentary on population screening for fragile $\mathrm{X}$ syndrome. Genet Med. 2010;12:411-412.

2. Godler DE, Tassone F, Loesch DZ, et al. Methylation of novel markers of fragile $\mathrm{X}$ alleles is inversely correlated with FMRP expression and FMR1 activation ratio. Hum Mol Genet 2010;19:1618-1632.

3. Hagerman RJ, Berry-Kravis E, Kaufmann WE, et al. Advances in the treatment of fragile X syndrome. Pediatrics 2009;123:378-390. 